\title{
Seasonal influenza vaccination and the risk of infection with pandemic influenza: a possible illustration of non- specific temporary immunity following infection
}

H Kelly (heath.kelly@mh.org.au) 1 , S Barry ${ }^{2}$, K Laurie³, G Mercer ${ }^{2}$

1. Victorian Infectious Diseases Reference Laboratory, Melbourne, Australia

2. National Centre for Epidemiology and Population Health, Australian National University, Canberra, Australia

3. World Health Organization Collaborating Centre for Reference and Research on Influenza, Melbourne, Australia

Citation style for this article:

Kelly H, Barry S, Laurie K, Mercer G. Seasonal influenza vaccination and the risk of infection with pandemic influenza: a possible illustration of non-

specific temporary immunity following infection. Euro Surveill. 2010;15(47):pii=19722. Available online: http://www.eurosurveillance.org/ViewArticle. aspx?Articleld $=19722$

Article published on 25 November 2010

Four Canadian studies have suggested that receipt of seasonal influenza vaccine increased the risk of laboratory-confirmed infection with 2009 pandemic influenza $A\left(\mathrm{H}_{1} \mathrm{~N}_{1}\right)$. During the influenza season of 2009 in Victoria, Australia, this virus comprised $97 \%$ of all circulating influenza viruses for which sub-typing was available. We found no evidence that seasonal influenza vaccine increased the risk of, or provided protection against, infection with the pandemic virus. Ferret experiments have suggested protection against pandemic influenza $A\left(\mathrm{H}_{1} \mathrm{~N}_{1}\right) 2009$ from multiple prior seasonal influenza infections but not from prior seasonal vaccination. Modelling studies suggest that influenza infection leads to heterosubtypic temporary immunity which is initially almost complete. We suggest these observations together can explain the apparent discrepant findings in Canada and Victoria. In Victoria there was no recent prior circulation of seasonal influenza and thus no temporary immunity to pandemic influenza. There was no association of seasonal influenza vaccine with pandemic influenza infection. In Canada seasonal influenza preceded circulation of the pandemic virus. An unvaccinated proportion of the population developed temporary immunity to pandemic influenza from seasonal infection but a proportion of vaccinated members of the population did not get seasonal infection and hence did not develop temporary immunity to pandemic influenza. It may therefore have appeared as if seasonal vaccination increased the risk of infection with pandemic influenza $A\left(\mathrm{H}_{1} \mathrm{~N}_{1}\right)$ virus.

\section{Introduction}

Four Canadian studies have recently suggested that receipt of seasonal influenza vaccine increased the risk of infection with 2009 pandemic influenza $A\left(\mathrm{H}_{1} \mathrm{~N}_{1}\right)$ 1.4- $^{-}$ 2.5-fold [1]. The authors of these studies advanced two hypotheses to explain these unexpected observations. Firstly they suggested that the seasonal influenza vaccine effectively blocked cumulative infections with seasonal influenza viruses, thus preventing the induction of cross-reactive immunity which may have protected from pandemic influenza $A\left(\mathrm{H}_{1} \mathrm{~N}_{1}\right)$ infection. They referred to this as the 'cross-protection block hypothesis' but argued that unrealistically high values for seasonal influenza vaccine effectiveness and seasonal influenza attack rates needed to be assumed for this hypothesis to produce odds ratios consistent with their observations (Appendix G in reference [1]). Secondly, based on the concept of antibody-dependent enhancement (ADE) of virus replication, they argued that vaccination against one or more influenza strains actually increased the risk of infection with a subsequent heterosubtypic strain that was antigenically remote from any of the vaccine strains [1]. According to this hypothesis, low levels of pre-existing weakly heterotypic or heterosubtypic antibodies promoted virus endocytosis and subsequent replication, increasing viral load production. In ferrets challenged with a lethal virus following immunisation with a non-adjuvanted human vaccine known not to provide protection to naïve animals, the previous vaccination with a heterosubtypic strain appeared harmful [2]. This observation supported the hypothesis of possible ADE, although we believe these studies might not be transferable to humans.

In Victoria, Australia, we found no evidence of increased risk of laboratory proven pandemic influenza $\mathrm{A}\left(\mathrm{H}_{1} \mathrm{~N}_{1}\right)$ infection in a population that had previously received only seasonal influenza vaccine [3]. Pandemic influenza occurred during the southern hemisphere influenza season of 2009 and, in Victoria, comprised more than $97 \%$ of all circulating influenza viruses for which sub-typing was available [4]. This would have been the perfect setting to have demonstrated ADE of viral replication if it were a general phenomenon, given that pandemic influenza $A\left(\mathrm{H}_{1} \mathrm{~N}_{1}\right)$ is a quadruple reassortant virus that is antigenically distant from recently circulating strains and that there was a significant antigenic distance between the vaccine and circulating strains of influenza [5]. However we found no evidence of increased risk of seasonal influenza 
amongst recipients of the seasonal influenza vaccine, with an estimated age adjusted odds ratio of 0.97 (95\% confidence interval (Cl): 0.6-1.56) [3]. A household study in Western Australia found a similar result with an adjusted odds ratio of 1.0 (95\% Cl: 0.7-1.5), although this study used influenza-like illness rather than laboratory-confirmed influenza as its outcome [6]. Laboratory-confirmed influenza was the outcome assessed in both Canada [1] and Victoria [3].

Based on a series of ferret experiments we have found that experimental infection(s) with seasonal influenza decreased the risk of infection subsequent to challenge with pandemic influenza, but that vaccination with adjuvanted seasonal influenza vaccine provided neither protection or enhancement, even with high levels of antibodies [7]. On the other hand, vaccination with adjuvanted human seasonal influenza vaccine protected the ferrets from seasonal influenza infection.

\section{The temporary immunity hypothesis}

We would like to suggest an alternative hypothesis to explain the findings from both Canada and Victoria. In our hypothesis recent infection with any strain of influenza would confer temporary immunity to infection with any other strain, independent of antigenic distance, but vaccination would not confer protection unless the vaccine and circulating strains were antigenically similar.

Although it is not an accepted immune phenomenon, the concept of temporary immunity has been explored in the modelling literature for a number of years. In 2003 Ferguson et al. reported that 'short-lived straintranscending immunity' was necessary to reproduce what was known from 'epidemiological dynamics and viral evolution at the sequence level' in order to restrict viral diversity and produce influenza drift dynamics with seasonal patterns [8]. Without non-specific temporary immunity, simulations produce more divergent strains than are demonstrated by surveillance. The concept has subsequently been supported by other investigators, including Tria et al. [9], Omori et al. [10]; and our own modelling [11]. It has been further elaborated in a series of papers by Minayev and Ferguson $[12,13]$.

\section{The biology of temporary immunity}

Type I interferons and other cytokines have been suggested as mediators of this phenomenon by inducing an antiviral state in infected, and neighbouring, epithelial cells [14]. In a guinea pig model of influenza infection, daily intranasal administration of recombinant human interferon alpha completely blocked transmission of pandemic influenza $A\left(\mathrm{H}_{1} \mathrm{~N}_{1}\right)$ both from and to treated animals [15]. Further, prophylaxis with interferon alpha reduced virus shedding of ferrets and guinea pigs infected with highly pathogenic influenza strains and morbidity following seasonal influenza challenge $[16,17]$.
Protection from symptomatic infection may also be mediated by T-cell immunity, specific for conserved epitopes in heterosubtypic influenza strains $[7,15,18]$, and B-cell immunity through antibodies specific for common epitopes, generally between homosubtypic strains $[19,20]$. Animal models of influenza have shown that prior infection(s) with seasonal influenza strains reduce transmission and virus shedding of pandemic influenza $A\left(\mathrm{H}_{1} \mathrm{~N}_{1}\right)$ virus $[7,15]$.

Temporary immunity induced by previous experimental infection has also been demonstrated to reduce morbidity and mortality following highly pathogenic influenza challenge [18]. We suggest temporary immunity may be mediated by a combination of innate and adaptive immune responses. Protection provided by temporary immunity may vary with age but would be expected to be immediately higher than that provided by antibody-mediated cross-protection alone.

The duration of temporary immunity is a critical issue in this hypothesis but is not yet clearly defined. On theoretical grounds Ferguson et al. suggested that following infection, temporary immunity would initially protect any infected person against all influenza strains before waning with time (supplementary material in reference [8]). Most models simulate temporary immunity using rate equations decaying with an exponential half life. $A$ mean duration of temporary immunity of three months is credible in modelling with seasonality, since immunity needs only to last as long as the influenza season. If it lasts too long it does not allow the next season epidemic to start; if it is too short, too many strains proliferate.

\section{Evidence for temporary \\ immunity in humans}

In a re-analysis of data from school surveys following the 1918-19 pandemic in England and Wales, Mathews et al. have suggested that temporary immunity is one of the mechanisms that need to be invoked to explain the observed wave phenomenon of that pandemic [21]. The authors also calculated odds ratios for infection with a second influenza sub-type following infection with a different primary sub-type from published studies of the influenza $A\left(\mathrm{H}_{2} \mathrm{~N}_{2}\right)$ pandemic of 1957-8 and the re-emergence of influenza $A\left(\mathrm{H}_{1} \mathrm{~N}_{1}\right)$ in 1977 [21]. Slepushkin studied a group of factory workers and reported that workers with symptoms during the seasonal influenza $A\left(\mathrm{H}_{1} \mathrm{~N}_{1}\right)$ outbreak in the spring of 1957 were less likely to be symptomatic when the new influenza $\mathrm{A}\left(\mathrm{H}_{2} \mathrm{~N}_{2}\right)$ appeared [22]. The calculated odds ratio was 0.4 (95\% Cl: 0.3-0.6) [21]. Sonoguchi et al. reported protection from influenza $A\left(\mathrm{H}_{1} \mathrm{~N}_{1}\right)$ infection in Japanese school children who had previously been infected with influenza $A\left(\mathrm{H}_{3} \mathrm{~N}_{2}\right)$ when influenza $A\left(\mathrm{H}_{1} \mathrm{~N}_{1}\right)$ re-emerged in 1997-8 [23]. When exposure was separated only by days or weeks, the calculated odds ratios for a second infection, given primary infection with a different subtype, was calculated as 0.06 (95\% 
$\mathrm{Cl}: 0.02-0.13)$ for high school students and 0.2 (95\% $\mathrm{Cl}$ : 0.08-0.3) for primary school students [21].

Extending this hypothesis, and further suggesting that temporary immunity may be conferred not only by influenza infections but also by other viral infections, is a contemporary report from Sweden that rhinovirus infection may have decreased the risk of infection with pandemic influenza $A\left(\mathrm{H}_{1} \mathrm{~N}_{1}\right)$ by what was suggested to be a cytokine-mediated phenomenon [24].

\section{Temporary immunity following seasonal influenza virus circulation in Canada and Australia}

If the temporary immunity hypothesis is valid, and if the seasonal influenza vaccine provided no protection against pandemic influenza, we would have expected no protection against pandemic influenza $A\left(\mathrm{H}_{1} \mathrm{~N}_{1}\right)$ in Victoria in 2009, when there was minimal circulation of any seasonal influenza virus prior to the introduction of pandemic influenza $A\left(\mathrm{H}_{1} \mathrm{~N}_{1}\right)$ [3]. In Victoria there was no opportunity for temporary immunity to develop.

However our expectations in Canada would have been different, given that seasonal influenza circulated with peak incidence eleven weeks before the first notified cases of pandemic influenza $A\left(\mathrm{H}_{1} \mathrm{~N}_{1}\right)$. Canadians who had received seasonal influenza vaccine had approximately $50 \%$ protection against seasonal infection [1] and would have foregone the potential temporary immunity induced by seasonal infection. However temporary immunity to pandemic influenza $A\left(\mathrm{H}_{1} \mathrm{~N}_{1}\right)$ would have been induced in unvaccinated Canadians who had a seasonal influenza infection. This may have resulted in an apparent increased risk of pandemic influenza $A\left(\mathrm{H}_{1} \mathrm{~N}_{1}\right)$ infection in people vaccinated against seasonal influenza.

We explored the temporary immunity hypothesis, making a range of assumptions about seasonal influenza vaccine effectiveness (VE) and seasonal and pandemic influenza infection rates (the cumulative incidence of infection). Our primary assumption was that there was no protection from pandemic influenza following receipt of the seasonal influenza vaccine. We also assumed there was no risk associated with vaccination, implying that for seasonal influenza vaccine $V E=0$ against pandemic influenza $A\left(\mathrm{H}_{1} \mathrm{~N}_{1}\right)$ infection.

In a case-control study VE is estimated as 1-OR, where $O R$ is the odds ratio. We considered a theoretical casecontrol study and calculated the OR for the outcome of pandemic infection given the exposure to seasonal vaccination. We used a method similar to that outlined in Skowronski et al. (Appendix G in reference [1]). We let $\theta_{\mathrm{s}}$ be the seasonal infection rate, $\theta_{\mathrm{p}}$ the pandemic infection rate and a the proportion of temporary immunity afforded by a recent seasonal influenza infection.
The probability of a vaccinated individual being infected with pandemic influenza $A\left(\mathrm{H}_{1} \mathrm{~N}_{1}\right)$ can be expressed as

$p_{V}=\left[\theta_{S}{ }^{*}(1-V E){ }^{\star}(1-a)+\theta_{S}{ }^{*} V E+\left(1-\theta_{S}\right)\right]^{*} \theta_{P^{*}}$

This formula acknowledges there are three ways a vaccinated individual could have become infected with pandemic influenza $\mathrm{A}\left(\mathrm{H}_{1} \mathrm{~N}_{1}\right)$ : first, the individual was exposed to seasonal influenza and infected $\left(\theta_{\mathrm{s}}\right)$, vaccination was not effective (1-VE) and there was no temporary immunity (1- a); second, the individual was exposed to seasonal influenza but the vaccine was effective (VE), so that the individual was not infected with seasonal influenza and therefore had no temporary immunity; third, the individual was not exposed to seasonal influenza and therefore not infected $\left(1-\theta_{\mathrm{s}}\right)$, and hence had no temporary immunity. In each case the individual had $\theta P$ chance of infection with pandemic influenza.

Similarly the probability for an unvaccinated individual being infected with pandemic influenza $A\left(\mathrm{H}_{1} \mathrm{~N}_{1}\right)\left(p_{u}\right)$ is given by

$p_{u}=\left(\theta_{S}^{*}(1-a)+\left(1-\theta_{S}\right)\right)^{*} \theta_{p}$

The odds ratio is calculated as $p_{v}\left(1-p_{u}\right) /\left(\left(1-p_{v}\right) * p_{u}\right)$.

We assumed a seasonal influenza VE of $70 \%$, consistent with estimates from the Cochrane review of healthy adults for matched circulating and vaccine strains [25], and seasonal and pandemic infection rates (that is,

\section{FIGURE}

Odds ratio of seasonal vaccination comparing patients with and without pandemic influenza infection and proportion of patients with temporary immunity to pandemic influenza following seasonal influenza infection

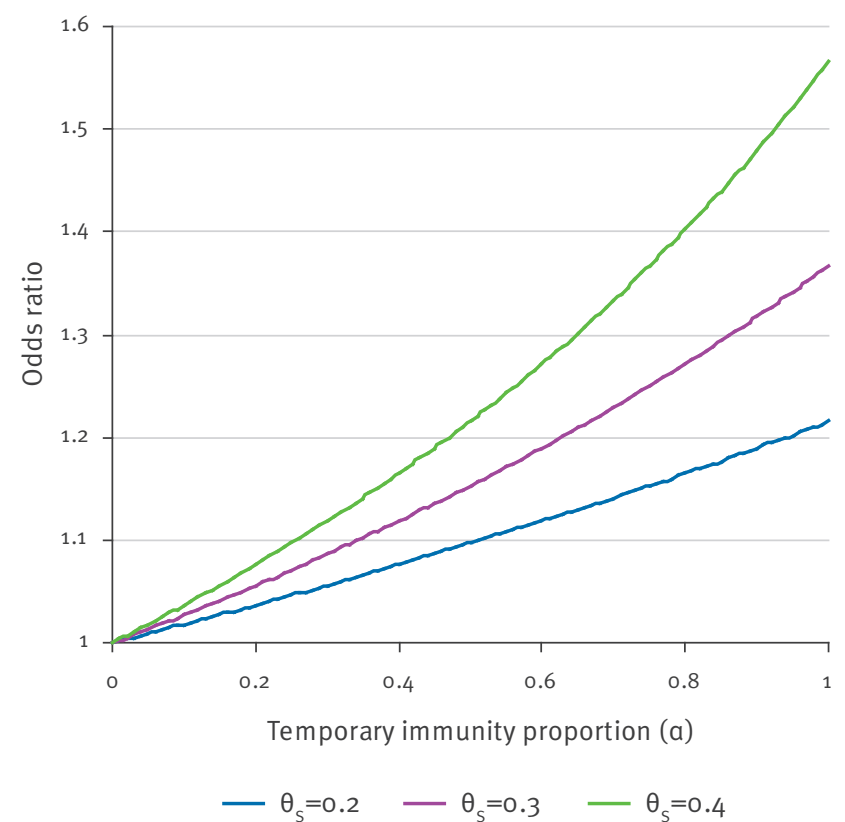

$\theta_{s}$ : seasonal influenza infection rate.

Seasonal influenza vaccine effectiveness was set at $70 \%$. 
seasonal cumulative incidence of serologically confirmed infection) between 20 and $40 \%$, broadly consistent with community studies of seasonal influenza [26] and serological studies of pandemic influenza [27]. For these parameters, we found an odds ratio between approximately 1.2 and 1.5 comparing vaccinated and unvaccinated people infected with pandemic influenza, if temporary immunity from recent previous infection was assumed to be of the order of $80-90 \%$ (Figure). As previously noted, temporary immunity was modelled to be $100 \%$ initially. The odds ratio increased for higher seasonal VE, higher cumulative incidence of infection and a higher population proportion of temporary immunity. All calculations assumed that there was no protection and no risk from seasonal vaccination against pandemic infection.

\section{Discussion}

We suggest that temporary immunity following infection may explain the apparently conflicting findings that the seasonal influenza vaccine provided no protection from pandemic infection in Victoria but increased the risk of pandemic infection in Canada. Assuming that the seasonal influenza vaccine had no effect on the risk of pandemic infection, we have shown that temporary immunity from seasonal infection will result in an apparent increase in risk, due to a proportion of vaccinated individuals being infected with pandemic influenza having foregone the temporary protection from seasonal infection. Using a simple susceptibleinfected-recovered (SIR) model we have extended our analysis to include the effect of time, and have confirmed that the temporary immunity hypothesis can account for the apparently discrepant findings [11].
This phenomenon would only be observed where pandemic virus circulation occurred within two to three months of seasonal virus circulation, allowing sufficient time for temporary immunity to develop and to wane. This was seen in parts of the northern, but not the southern, hemisphere. Because of the timing of seasonal and pandemic virus circulation, we might also have expected to see the apparent harmful effect of seasonal influenza vaccine in the United States and the United Kingdom. We would not have expected to see the effect in any northern hemisphere country that experienced only one wave of pandemic influenza $A\left(\mathrm{H}_{1} \mathrm{~N}_{1}\right)$ virus circulation at the time that other countries experienced a second wave, because temporary immunity from prior seasonal influenza infection would have decayed by the time the second wave commenced. Assuming that people infected in the first wave were not infected again in the second wave, neither would we expect to see the apparently harmful effect of seasonal vaccination during a second wave in a country that experienced a first wave, again because temporary immunity from prior seasonal influenza infection would have decayed. The absence of an apparently harmful (or protective) effect of seasonal influenza vaccine during the second pandemic wave in Canada supports this expectation [28].

However, a range of VE results for seasonal vaccination against pandemic influenza infection have now been reported, only some of which can be explained by the temporary immunity hypothesis (Table). The studies from Mexico $[29,30]$ showing protection from pandemic infection following seasonal vaccination are not consistent with one of the assumptions in our model,

\section{TABLE}

Reported odds ratios and vaccine effectiveness for the association of seasonal influenza vaccine and pandemic influenza infection, by study site, 2009

\begin{tabular}{|c|c|c|c|}
\hline Location & 2009 & $\begin{array}{c}\text { Odds ratio } \\
\text { (95\% confidence interval) }\end{array}$ & $\begin{array}{l}\text { Vaccine effectiveness }(\%) \\
\text { (95\% confidence interval) }\end{array}$ \\
\hline United States, military [33] & Apr-May & $2.90(1.84,4.57)$ & $-190(-357,-84)$ \\
\hline Canada $[1] \times 4$ & Apr-July & $1.4-2.5(1.03,2.74)$ & $-68(-174,-3)$ \\
\hline Castellon, Spain [34] & Oct -Jan 2010 & $\begin{array}{c}1.20(0.62-2.34) \\
2008-9 \text { seasonal influenza vaccine }\end{array}$ & $-20(-134,38)$ \\
\hline United States [35] & May-Jun & $1.10(0.85,1.46)$ & $-10(-46,15)$ \\
\hline United States, university [36] & Mar-May & $1.10(0.90,1.40)$ & $-10(-40,10)$ \\
\hline United States, school [37] & Apr & $1.05(0.91,1.20)$ & $-5(-20,9)$ \\
\hline Castellon, Spain [34] & Oct -Jan 2010 & $\begin{array}{c}0.96(0.50,1.86) \\
2009-10 \text { seasonal influenza vac- } \\
\text { cine }\end{array}$ & $+4(-86,50)$ \\
\hline Victoria [3] & Apr-Dec & $0.97(0.60,1.56)$ & $+3(-56,40)$ \\
\hline Western Australia [6] & May-Aug & $1.00(0.70,1.50)$ & $0(-50,30)$ \\
\hline Mexico [30] & Apr-July & $0.65(0.55,0.77)$ & $+35(23,45)$ \\
\hline Mexico, hospital [29] & Mar-May & $0.27(0.11,0.66)$ & $+73(34,89)$ \\
\hline
\end{tabular}


that seasonal vaccine provided no protection against pandemic infection. However both these studies have been reasonably criticised on methodological grounds $[31,32]$. While some protection is biologically plausible, based on the demonstration of cross-reacting antibodies to pandemic influenza $A\left(\mathrm{H}_{1} \mathrm{~N}_{1}\right)$ virus, it would be expected mostly in older people. The findings from the other studies listed in the Table are consistent with the temporary immunity hypothesis.

As described above, the temporary immunity hypothesis suggests that one would only find an apparent increase in the risk of pandemic influenza infection associated with the receipt of seasonal influenza vaccination where the circulation of pandemic influenza virus followed that of seasonal influenza virus within a few weeks to months. Recognising this phenomenon would depend on infection rates with both viruses and seasonal influenza vaccine coverage, with the association more evident where seasonal and pandemic influenza infection rates and seasonal influenza vaccine coverage were higher. We suggest that odds ratios up to 1.5 can be explained by this hypothesis using plausible values for infection rates and seasonal influenza vaccine effectiveness. However we agree with Skowronski et al. that a high level of immunity, due to temporary immunity in our hypothesis or cross protection in their hypothesis, is needed to completely explain the apparent harmful association of seasonal influenza vaccination with pandemic influenza infection [1].

\section{Acknowledgements}

We thank Dr Benjamin Cowie and Dr Marta Valenciano for their helpful comments. Kristina Grant and Francine Cousinery assisted with preparation of the manuscript. The Melbourne WHO Collaborating Centre for Reference and Research on Influenza is supported by the Australian Government Department of Health and Ageing. Dr Geoffry Mercer and Dr Steven Barry are supported in part by a grant from the National Health and Medical Research Council of Australia.

\section{References}

1. Skowronski DM, De Serres G, Crowcroft NS, Janjua NZ, Boulianne N, Hottes TS, et al. Association between the 2008og seasonal influenza vaccine and pandemic $\mathrm{H}_{1} \mathrm{~N}_{1}$ illness during Spring-Summer 2009: four observational studies from Canada. PLoS Med.7(4):e1000258.

2. Kobinger GP, Meunier I, Patel A, Pillet S, Gren J, Stebner S, et al. Assessment of the efficacy of commercially available and candidate vaccines against a pandemic $\mathrm{H}_{1} \mathrm{~N}_{1} 2009$ virus. J Infect Dis. 201(7):1000-6.

3. Kelly H, Grant, K. Interim analysis of pandemic influenza $\left(\mathrm{H}_{1} \mathrm{~N}_{1}\right) 2009$ in Australia: surveillance trends, age of infection and effectiveness of seasonal vaccination. Euro Surveill. 2009;14(31):pii=19288. Available from: http://www. eurosurveillance.org/ViewArticle.aspx?Articleld=19288

4. Fielding J, Higgins N, Gregory J, Grant K, Catton M, Bergeri I, et al. Pandemic $\mathrm{H}_{1} \mathrm{~N}_{1}$ influenza surveillance in Victoria, Australia, April - September, 2009. Euro Surveill. 2009;14(42):pii:19368. Available from: http://www.eurosurveillance.org/ViewArticle. aspx?Articleld $=19368$

5. Tang JW, Tambyah PA, Wilder-Smith A, Puong KY, Shaw R, Barr IG, et al. Cross-reactive antibodies to pandemic $\left(\mathrm{H}_{1} \mathrm{~N}_{1}\right) 2009$ virus, Singapore. Emerg Infect Dis. 2010;16(5):874-6.
6. Carcione D, Giele C, Goggin LS, Kwan KS, Smith DW, Dowse GK, et al. Association between 2009 seasonal influenza vaccine and influenza-like illness during the 2009 pandemic: preliminary results of a large household transmission study in Western Australia. Euro Surveill. 2010;15(28): pii=19616. Available from: http://www.eurosurveillance.org/ViewArticle. aspx?Articleld=19616

7. Laurie KL, Carolan LA, Middleton D, Lowther S, Kelso A, Barr IG. Multiple infections with seasonal influenza A virus induce cross-protective immunity against $A\left(\mathrm{H}_{1} \mathrm{~N}_{1}\right)$ pandemic influenza virus in a ferret model. J Infect Dis. 2010;202(7):1011-20.

8. Ferguson NM, Galvani AP, Bush RM. Ecological and immunological determinants of influenza evolution. Nature. 2003:422(6930):428-33.

9. Tria F, Lässig M, Peliti L, Franz S. A minimal stochastic model for influenza evolution. J Stat Mech. 2005;P07008.

10. Omori R, Adams B, Sasaki A. Coexistence conditions for strains of influenza with immune cross-reaction. J Theor Biol. 2010;262(1):48-57.

11. Mercer GN, Barry SI, Kelly H. Modelling the association of seasonal influenza vaccination and the risk of infection with pandemic influenza. BMC Public Health. 2010; Forthcoming.

12. Minayev $P$, Ferguson NM. Improving the realism of deterministic multi-strain models: implications for modelling influenza A. J R Soc Interface. 2009;6(35):509-18.

13. Minayev P, Ferguson NM. Incorporating demographic stochasticity into multi-strain epidemic models: application to influenza A. J R Soc Interface. 2009;6(40):989-96.

14. Malmgaard L. Induction and regulation of IFNs during viral infections. J Interferon Cytokine Res. 2004;24(8):439-54.

15. Steel J, Staeheli P, Mubareka S, Garcia-Sastre A, Palese P, Lowen AC. Transmission of pandemic $\mathrm{H}_{1} \mathrm{~N}_{1}$ influenza virus and impact of prior exposure to seasonal strains or interferon treatment. J Virol. 201084(1):21-6.

16. Van Hoeven N, Belser JA, Szretter KJ, Zeng H, Staeheli P, Swayne DE, et al. Pathogenesis of 1918 pandemic and $\mathrm{H}_{5} \mathrm{~N}_{1}$ influenza virus infections in a guinea pig model: antiviral potential of exogenous alpha interferon to reduce virus shedding. J Virol. 2009;83(7):2851-61.

17. Kugel D, Kochs G, Obojes K, Roth J, Kobinger GP, Kobasa D, et al. Intranasal administration of alpha interferon reduces seasonal influenza A virus morbidity in ferrets. J Virol. 2009;83(8):3843-51.

18. Bodewes R, Kreijtz JH, Baas C, Geelhoed-Mieras MM, de Mutsert $\mathrm{G}$, van Amerongen $\mathrm{G}$, et al. Vaccination against human influenza $\mathrm{A} / \mathrm{H}_{3} \mathrm{~N}_{2}$ virus prevents the induction of heterosubtypic immunity against lethal infection with avian influenza A/H5N1 virus. PLoS One. 2009;4(5):e5538.

19. Manicassamy B, Medina RA, Hai R, Tsibane T, Stertz S, NistalVillán E, et al. Protection of mice against lethal challenge with $2009 \mathrm{H}_{1} \mathrm{~N}_{1}$ influenza A virus by 1918 -like and classical swine H1N1 based vaccines. PLos Pathog. 2009;6:e1000745.

20. Hancock K, Veguilla V, Lu X, Zhong W, Butler EN, Sun H, et al. Cross-reactive antibody responses to the 2009 pandemic $\mathrm{H}_{1} \mathrm{~N}_{1}$ influenza virus. N Engl J Med. 2009;361(20):1945-52.

21. Mathews JD, McBryde ES, McVernon J, Pallaghy PK, McCaw JM. Prior immunity helps to explain wave-like behaviour of pandemic influenza in 1918-9. BMC Infect Dis. 2010;10:128.

22. Slepushkin AN. The effect of a previous attack of $A 1$ influenza on susceptibility to A2 virus during the 1957 outbreak. Bull World Health Organ. 1959;20(2-3):297-301.

23. Sonoguchi T, Naito H, Hara M, Takeuchi Y, Fukumi H. Crosssubtype protection in humans during sequential, overlapping, and/or concurrent epidemics caused by $\mathrm{H}_{3} \mathrm{~N}_{2}$ and $\mathrm{H}_{1} \mathrm{~N}_{1}$ influenza viruses. J Infect Dis. 1985;151(1):81-8.

24. Linde A, Rotzen-Ostlund M, Zweygberg-Wirgart B, Rubinova S Brytting $M$. Does viral interference affect spread of influenza? Euro Surveill. 2009;14(40):pii=19354. Available from: http:// www.eurosurveillance.org/ViewArticle.aspx?Articleld $=19354$

25. Jefferson TO, Rivetti D, Di Pietrantonj C, Rivetti A, Demicheli V. Vaccines for preventing influenza in healthy adults. Cochrane Database Syst Rev. 2007(2):CDo01269.

26. Fox JP, Hall CE, Cooney MK, Foy HM. Influenzavirus infections in Seattle families, 1975-1979. I. Study design, methods and the occurrence of infections by time and age. Am J Epidemiol. 1982;116(2):212-27.

27. Miller E, Hoschler K, Hardelid P, Stanford E, Andrews N, Zambon M. Incidence of 2009 pandemic influenza $\mathrm{A} \mathrm{H}_{1} \mathrm{~N}_{1}$ infection in England: a cross-sectional serological study. Lancet. 2010;375(9720):1100-8. 
28. Skowronski DM, Janjua N, De Serres G, Hottes T et al. Analysis of the association between 2008-09 trivalent influenza vaccine (TIV) and pandemic A/H1N1 risk during the fall 2009. Options for the Control of Influenza VII; 2010; Hong Kong SAR, China. Available at http://www.controlinfluenza.com/abstracts/index. cfm?m=view\&id=4405

29. Garcia-Garcia L, Valdespino-Gomez JL, Lazcano-Ponce E, Jimenez-Corona A, Higuera-Iglesias A, Cruz-Hervert P, et al. Partial protection of seasonal trivalent inactivated vaccine against novel pandemic influenza $A / \mathrm{H}_{1} \mathrm{~N}_{1}$ 2009: case-control study in Mexico City. BMJ. 2009;339:b3928.

30. Echevarria-Zuno S, Mejia-Arangure JM, Mar-Obeso AJ, GrajalesMuniz C, Robles-Perez E, Gonzalez-Leon M, et al. Infection and death from influenza $A \mathrm{H}_{1} \mathrm{~N}_{1}$ virus in Mexico: a retrospective analysis. Lancet. 2009;374(9707):2072-9.

31. Janjua NZ, Skowronski DM, Hottes TS, De Serres G, Crowcroft NS, Rosella LC. Seasonal vaccine and $\mathrm{H}_{1} \mathrm{~N}_{1}$. Selection bias explains seasonal vaccine's protection. BMJ. 2009;339:b4972.

32. Janjua NZ, Skowronski DM, Hottes TS, De Serres G, Crowcroft NS, Rosella LC. Seasonal vaccine effectiveness against pandemic A/H1N1. Lancet. 2010;375(9717):801-2.

33. Crum-Cianflone NF, Blair PJ, Faix D, Arnold J, Echols S, Sherman SS, et al. Clinical and epidemiologic characteristics of an outbreak of novel $\mathrm{H}_{1} \mathrm{~N}_{1}$ (swine origin) influenza A virus among United States military beneficiaries. Clin Infect Dis. 2009;49(12):1801-10.

34. Puig-Barbera J, Arnedo-Pena A, Pardo-Serrano F, TiradoBalaguer MD, Perez-Vilar S, Silvestre-Silvestre E, et al. Effectiveness of seasonal 2008-2009, 2009-2010 and pandemic vaccines, to prevent influenza hospitalizations during the autumn 2009 influenza pandemic wave in Castellon, Spain. A test-negative, hospital-based, case-control study. Vaccine. 2010;28(47):7460-7.

35. Centers for Disease Control and Prevention (CDC).

Effectiveness of 2008-09 trivalent influenza vaccine against 2009 pandemic influenza A ( $\left.\mathrm{H}_{1} \mathrm{~N}_{1}\right)$ - United States, May-June 2009. MMWR Morb Mortal Wkly Rep. 2009;58(44):1241-5.

36. Iuliano AD, Reed C, Guh A, Desai M, Dee DL, Kutty P, et al. Notes from the field: outbreak of 2009 pandemic influenza $A$ $\left(\mathrm{H}_{1} \mathrm{~N}_{1}\right)$ virus at a large public university in Delaware, April-May 2009. Clin Infect Dis. 2009;49(12):1811-20.

37. Lessler J, Reich NG, Cummings DA, Nair HP, Jordan HT, Thompson N. Outbreak of 2009 pandemic influenza $A\left(\mathrm{H}_{1} \mathrm{~N}_{1}\right)$ at a New York City school. N Engl J Med. 2009;361(27):2628-36 